\title{
Experience, Innovation and Productivity Empirical Evidence from Italy's Slowdown
}

\author{
Francesco Daveri \\ Maria Laura Parisi
}

CESIFO WORKING PAPER No. 3123

CATEGORY 4: LABOUR MARKETS

JULY 2010
An electronic version of the paper may be downloaded
- from the SSRN website: Www.SSRN.com
- from the RePEc website: $\quad$ www.RePEc.org
- from the CESifo website: www.CESifo-group.org/wp




\title{
Experience, Innovation and Productivity Empirical Evidence from Italy's Slowdown
}

\begin{abstract}
We investigate the role of workers' and managerial experience as a determinant of firm innovation and productivity in a sample of Italian manufacturing firms. A high share of temporary - thus un-experienced - workers is associated to low innovation and productivity. The effect of managerial experience measured by age on firm performance depends instead on the type of firm: high age of managers and board members is bad for innovation and productivity growth, while costs and benefits of old managerial age cancel out for noninnovative firms.
\end{abstract}

JEL-Code: M54, O31, D24.

Keywords: firm productivity, innovation, managerial experience, temporary jobs.

\author{
Francesco Daveri \\ Department of Economics \\ University of Parma \\ Via Kennedy, 6 \\ Italy-43100 Parma \\ daveri@unipr.it
}

\author{
Maria Laura Parisi \\ Department of Economics \\ University of Brescia \\ via San Faustino 74/b \\ Italy - 25122 Brescia \\ parisiml@yahoo.it
}

Earlier drafts of this paper have been presented at Aix-en-Provence (conference: "Firms, Trade and Development"), Munich (OECD-CESifo conference "Regulation: Political Economy, Measurement and Effects on Performance") and the Istituto Studi per l'Analisi Economica (ISAE) in Rome. We are grateful to our discussants Remy Lecat and Thomas Strobel, as well as other conference and seminar participants for their useful comments. 


\section{Introduction}

Innovation is one of the main drivers of productivity growth. It is thus no wonder that the study of its determinants has attracted considerable attention (Geroski 2000, Comin and Hobijn 2009). Extensive empirical evidence has documented that R\&D enhances firm innovation and productivity by enabling product innovation (Griliches, 1992; van Pottelsberghe de la Potterie, 2008) as well as easing the adoption of technologies developed in other firms and possibly countries (Griffith, Redding and van Reenen, 2004; Parisi, Schiantarelli and Sembenelli, 2006). The risky nature of innovation also makes it a typically hard-to-finance undertaking, which has led a number of scholars to investigate the enabling role of cash flows to avoid that liquidity constraints strangle yet undeveloped innovations in their infancy (Brown, Fazzari and Petersen, 2009, Geroski, van Reenen and Walters, 2002, Hall, Mairesse, Branstetter and Crépon, 1998).

Less investigated, and perhaps more controversial, is the relation between experience on one side and innovation and productivity on the other. Does it pay for a firm to be endowed with the breadth and the novelty of ideas brought about by newcomers on the entrepreneurial and the workers' side? Or do innovation and productivity gains mostly originate from the competence of older - hence mor experienced - workers and managers?

As discussed by Jones (2010), the case list of how un-experienced entrepreneurs and workers managed to develop and bring brand new products and technologies to the market are long. It starts with an un-experienced Bill Gates leaving Harvard in 1975 to co-found Microsoft with his friend Paul Allen, and continues with Steve Jobs and Steve Wozniak, the young founders of Apple. More recently, Sergei Brin and Larry Page, the co-founders of Google, were bright but young and unexperienced Stanford $\mathrm{PhD}$ students when they started thinking about the number and the informational content and nature of the links underlying the functioning of the World Wide Web. Yet we can also think of radical innovations brought about by more experienced workers and entrepreneurs, in some cases by the same grown-up entrepreneurs that had revolutionized their industry already once. It is still Steve Jobs who has made a tremendous comeback with his i-Pod, i- 
Phone and i-Pad devices. So at times managers grow old, but their ability to innovate does not necessarily fade away.

Even among scientists and artists, while there is widespread agreement that great innovations often come from the young and the un-experienced yet brilliant minds. Chicago economist David Galenson $(2003,2005,2007)$ has documented how the life-cycle of artists may be distinctively of two types, of a conceptual and an experiential type, so that the young genius of Van Gogh and Picasso, of Melville and Welles can be matched by the experienced ability of Michelangelo and Rembrandt, Paul Cezanne and Alfred Hitchcock. The relation between age and fundamental innovations in arts and science seems not to be linear as well.

Apart from scientists, artists and managers, this set of issues also has deep implications for workers. The productivity of individual workers depends on a host of characteristics, such as education and skills, experience, motivation, intellectual and physical abilities. Some of these worker characteristics - notably the productive value of skills - may deteriorate with age. Verhaegen and Salthouse (1997) present a meta-analysis of 91 studies on how mental abilities develop over the individual life span. Based on these studies, they conclude that the cognitive abilities (reasoning, speed and episodic memory) decline significantly just before 50 years of age and more thereafter. Maximum levels are instead achieved in the 20 s and the 30 s, independently of country and sex. Altogether, whether the good or the bad effects of experience actually prevail in practice is largely an empirical matter that can be usefully investigated with company data. In this paper we analyze the role of managerial and workers' experience in spurring (or depressing) firm-level innovation and productivity gains, exploiting firm-level data from the Italian economy in the early 2000s.

Italy in the early 2000s provides a fertile ground for studying the implications of experience for innovation and productivity. As shown in Table 1, since the second half of the 1990s a sharp productivity slowdown came about in the Italian economy, in spite of the fact that brand new technologies and managerial techniques had become available out there "on the shelf" thanks to the ICT revolution. Italy's productivity slowdown is not the consequence of unfortunate business cycle 
fluctuations.

Table 1. Growth of labor productivity in Italy, 1970-2003, main industry groups.

\begin{tabular}{|l|c|c|c|c|c|}
\hline & $\mathbf{1 9 7 0 - 8 0}$ & $\mathbf{1 9 8 0 - 9 5}$ & $\mathbf{1 9 9 5 - 0 3}$ & $1995-00$ & $2000-03$ \\
\hline Economy & 2.4 & 1.8 & 0.6 & 1.1 & -0.2 \\
\hline Agriculture & 3.1 & 4.3 & 2.7 & 5.2 & -1.5 \\
\hline Manufacturing & 2.8 & 3.0 & 0.2 & 1.0 & -1.0 \\
\hline-- non-durables & 2.7 & 3.1 & 0.3 & 0.7 & -0.2 \\
\hline-- durables & 2.9 & 2.7 & 0.0 & 1.7 & -2.7 \\
\hline Construction & 1.9 & 1.0 & 0.1 & 0.5 & -0.5 \\
\hline Business sector services & 1.8 & 1.1 & 0.1 & 0.5 & -0.5 \\
\hline
\end{tabular}

Source: Daveri and Jona-Lasinio, 2005

The sharp productivity slowdown started around 1995 in both manufacturing and service industries. Yet the zeroing of productivity growth in manufacturing - hence in "the" leading sector of the Italian economy in the past decades - is particularly worrisome and has taken place smoothly throughout the period but in a more pronounced fashion in 2001-03.

Experience may come into play to explain Italy's productivity slowdown in two ways. On the one hand, productivity fell in parallel with the introduction of piecemeal labor market reform which eased the entry of temporary (thus un-experienced) workers in the Italian labor market. Robert Gordon and Ian Dew-Becker (2008) conjectured that the process of labor market reform that occurred in many European countries in the second half of the 1990s, while helping Europe reverse the past tendencies towards job destruction, has been eventually detrimental to productivity growth. Simplifying their view to an extreme, if temporary job creation is allowed and labor demand does not shift outwards in parallel, labor supply shifts to the right along a given labor demand curve. No wonder that productivity declines as a result. This happened in Italy as well in 1997-98, when legislative changes gave full legal recognition to a host of contractual forms of part-time and temporary jobs, some of which had been in place even before though restricted to the unofficial labor market, while keeping job protection unchanged for permanent workers. The flurry of cheap labor from such half hearted labor market reforms likely translated into a decline of the equilibrium capital-labor ratio. Yet these legislative changes may have also discouraged the propensity to 
innovate of entrepreneurs, who found themselves confronted with the hard-to-resist temptation to adopt techniques intensively using part-time workers now abundantly available in the labor market instead of experimenting with (riskier) ICT-enabled innovation.

The other channel through which experience may have been important is on the manager side. The pace of adoption of ICT-related innovation was also possibly hampered by the unusually high presence of old, thus very experienced but perhaps possibly conservative (and very powerful) managers and board members, a reflection of the persisting lack of contestability of firm property rights in the Italian capital market. As discussed by Bandiera, Guiso, Prat and Sadun (2008), it turns out that only a fraction of firms - especially the non-family owned and multinationals - adopts a "performance-based" model, whereby managers are hired through business contacts and headhunting activities, undergo regular assessment procedures and are rewarded, promoted and dismissed on the basis of their assessment results. Most firms - particularly the family-owned ones and those mainly active in the domestic market - follow instead a "fidelity model" of managerial talent, hiring their managers based on personal or family contacts, which leaves formal assessment of performance in the background at best. In many ways, the fidelity model ends up selecting and keeping in office old managers well connected to their shareholders but only occasionally connected to market and technological developments. In short, the type of managerial model based on performance or fidelity - is tightly associated with the quality, the conduct and the performance of managers as well as of the firm itself. Firms blessed with faithful managers are often at a disadvantage when faced with new technological opportunities with respect to foreign competitors less dependent on family-based modes of running a firm. This state of affairs has been increasingly perceived as a severe constraint for the Italian economy, particularly when it has been exposed to the chance of reaping the technological and organizational benefits brought about by the Internet revolution in other countries.

The story may then be as follows. Labor market reform has channeled an inflow of relatively unexperienced workers into the Italian labor market. In parallel, the lack of financial market reform 
has instead kept the average age of those in charge of leading Italian companies unchanged, and this missing change (and "excess experience") is alleged to have lowered the propensity to innovate and the productivity performance of Italian firms. Gordon and Dew-Becker have not contrasted their ideas with micro data, while Bandiera, Guiso, Prat and Sadun have not looked at the interaction of labor market reform with the productivity and innovation counterpart of managerial practices. So there is room for comparing a streamlined version of the two views with company data. This is the main goal of our paper. More generally we believe that this combination of events and structural features is helpful for learning on the relation between experience, innovation and productivity.

In our study we employ a firm-level data set to separately analyze at the role of experience on the side of workers and the side of managers. Our preferred measure of experience on the workers' side is the average share of temporary workers in total employment. The increased presence of temporary workers in the Italian labor force has been a novelty of the late 1990s, which is portrayed in our company data. Our preferred measure of experience on the manager side is the average age of managers and board members in the Italian firms.

In doing so, we are confronted with (and we thus explicitly tackle) a few statistical hurdles, the first of which is the fundamentally cross-sectional nature of our data. The use of (long) differences for productivity growth (as opposed to productivity levels as most other studies such as Hall, Lotti and Mairesse (2007) allows us to lessen the simultaneity bias that would originate from regressing log levels of firm performance onto our variables of interest, such as managerial age or the share of temporary workers. Secondly, our preferred set of estimates is the result of a first stage where a regime switch from being non-innovative to innovative or the reverse may occur or not and a second stage.

Our evidence indicates that innovation and productivity growth was particularly low in firms with disproportionately high shares of temporary workers to start with. This result is robust to all changes of specifications. 
Yet declining productivity is also - slightly less robustly - associated to such managerial features as the average age of the managers running the companies. Our estimates separately run for innovative and non-innovative companies indicate that an older age of managers is associated with lower productivity in innovative firms and with higher productivity in non-innovative firms. This is consistent with common sense that suggests a more positive role of experience in firms with relatively standardized and stable business practices, while old age is presumably more damaging for innovative firms that would be supposed to swiftly adopt new technologies as they become available. This is presumably more tightly correlated with schooling and less with experience on the job. Our two-stage model results, while broadly confirming the robustness of the partial correlation between the share of temporary workers and productivity, shows that both product and process innovation are positively related with productivity growth. For the innovative firms age is negatively correlated with productivity growth and positively correlated or at times uncorrelated within the sample of non innovative firms, with little variation across estimation methods.

Our paper is structured as follows. In section 2, we discuss why and how experience should matter for innovation and productivity. In section 3 we describe the paper's conceptual underpinnings and estimation strategy. In section 4 we describe the main features of our data set. In section 5 we present our main results and some extensions. Section 6 concludes.

\section{Conceptual framework}

We consider a constant-returns-to-scale value-added production function. The full-fledged production function underlying equation (1) below would have (real) output on the left-hand side and capital, labor, intermediate inputs and services on the right-hand side. This would allow us to differentially treat the substitutability of such inputs with respect to capital and labor. Specifying the production function in terms of value added, however, lessens the endogenous input choice problem that plagues the estimates of production functions in general. Under the (untested) assumption of separability between the value added and the intermediates functions, the dependent variable may 
instead be real output less (real) materials and services. This implies that materials and services are no longer an argument in the production function.

Subject to these preliminary remarks and assumptions, in each period t, labor productivity (in logs) for firm $i$ at time $t$ may be decomposed as follows:

$$
\ln \left(Y_{i, t} / L_{i t}\right)=\ln \left(A_{i, t}\right)+\beta_{K} \ln \left(K_{i, t} / L_{i, t}\right)
$$

Equation (1) stems from a production function where (the $\log$ of) value added $\mathrm{Y}$ is a $\log$-linear function of the capital labor ratio $\mathrm{K} / \mathrm{L}$ and the efficiency parameter $\mathrm{A}$. In turn, $\mathrm{A}$ is a function of time and innovation as follows:

$\ln \left(A_{i t}\right)=\alpha * t * I N N O V A T I O N+$ error

The growth rate of the technological parameter is thus a linear function of INNOVATION. Under (1) and (2), the log difference (the growth rate) of labor productivity is a linear function of the growth rate of the capital-labor ratio and of the determinants of innovation.

In turn we assume that INNOVATION is a linear function of a few variables of interest including our preferred proxies for experience, i.e. firm-averaged managerial age and the share of part-time temporary workers in each firm, and other determinants of the decision to innovate (whether a firm undertakes R\&D spending, the share of R\&D workers in the total firm's labor force; cash flows) plus an array of regional, size and industry dummies, each affecting (the log of) A through a separate parameter.

Leaving aside the other determinants of innovation for expositional purpose, INNOVATION may be seen as a function of managerial experience and business schooling capital as follows:

INNOVATION $_{\mathrm{i}}=a \mathrm{E}_{\mathrm{i}}+b \mathrm{~S}_{\mathrm{i}}$

where $\mathrm{E}$ is experience and $\mathrm{S}$ is managerial capital formally accumulated going to the business school with $\mathrm{S}=\mathrm{T}-\mathrm{E}$. The variable "E" is the number of years a manager has spent doing her job inside or outside the firm. The variable " $\mathrm{S}$ " is the managerial capital accumulated at the business school by the manager under the time constraint $\mathrm{T}=\mathrm{E}+\mathrm{S}$, i.e. a manager either goes to the business 
school or learns on the job, so that the net effect of E on INNOVATION is positive or negative depending on whether $a>b$.

The intuition for (3) is simple. Traditional managerial techniques require on-the-job experience, while novel managerial techniques are those accumulated through off-the-job specific training or (business) schooling. This typically involves a trade-off, for a firm faces the decision to employ today a relatively experienced but old-fashioned manager or tomorrow a relatively un-experienced but well trained manager. It might also be that the marginal productivity of managerial experience and schooling is different across different categories of firms, such as between the so called innovative and non-innovative ones.

In practice, we empirically implement the logical framework described above in two stages. In the first stage firms are all alike but they contemplate the choice of innovating or not. As documented in previous studies, they are more likely to become innovative if they undertake R\&D and if endowed with enough cash-flows, as well as other location, size and industry time-invariant variables (captured by fixed effects in our empirical analysis). But the firm's propensity to innovate may also be affected by experience-related variables, whose role has not been much investigated before. Firms may innovate more if they do not employ too high a share of temporary workers as well as if they are endowed with relatively young managers. Once firms have selected themselves into innovative and non-innovative, experience as well as location, firm and size dummies are also allowed to affect productivity growth in the second stage, while R\&D and cash flow are not. The exclusion of R\&D and cash flows is thus our main identifying assumption.

\section{Empirical specification and strategy}

We search for the best empirical specification consistent with our data, starting from a baseline specification with no asymmetry between innovative and non-innovative firms. This baseline specification is the following: 


$$
\Delta_{2} \ln \left(\frac{Y}{L}\right)_{i, 2001-03}=\alpha \Delta_{2} \ln \left(\frac{K}{L}\right)_{i, 2001-03}+\beta+\gamma \overline{A g e}_{i, 2001}+\mu\left(\frac{\text { Temporary }}{L}\right)_{i, 2001}+\varepsilon_{i}
$$

The dependent variable is the 2001-03 growth rate of labor productivity for firm $i$ calculated at time $t=2003$, with respect to 2001. Age is calculated as the average age of the board members and managers when they were appointed. ${ }^{1}$ Temporary/L is the share of workers in the firm operating on a temporary contract (full time + part time) in 2001. In the regressions we control also for twentyone sector dummies, ${ }^{2}$ four geographical macro areas, ${ }^{3}$ size dummies for small, medium and large firms and firm membership in a group. Size is measured following the European Commission definition: firms with less than 50 workers are "Small"; firms with more than 50 but less than or equal 250 workers are "Medium"; firms with more than 250 employees are "Large".

Unfortunately, the IX Capitalia/Unicredit survey includes three years of observation only for a limited subset of our variables of interest. As to the determinants of innovation, in particular, we only have data for 2001, the initial year in our sample, and not for the three years between 2001 and 2003. ${ }^{4}$ Hence specification (4) is estimated by regressing the growth rate of labor productivity (hence the long difference of log productivity levels) on explanatory variables measured at a point in time, therefore within a cross sectional framework. Yet first differencing the log levels of labor productivity and the capital-labor ratio allows us to get rid of some of the unobserved heterogeneity between firms that represents the most obvious source of simultaneity bias.

As a second step in our empirical analysis, we run a Chow test of parameter instability on specification (4) to check whether there are significant asymmetries between innovative and noninnovative firms. It might be that because we expect the parameters $(\beta, \gamma, \mu)$ to differ between

\footnotetext{
${ }^{1}$ As a robustness check, we have also substituted as a regressor the average age of the board members with their seniority, i.e. the firm-board-average number of years in the board in 2001 (the initial year of our sample). This measure may however contain substantial measurement error given that we do not know when board members have quit or changed their role within the board before 2003. We have thus chosen not to report these results, which are however available upon request.

${ }^{2}$ The sector breakdown is based on the Ateco2007 classification of Italy's industries, in turn equivalent to the NACE rev.2 European code.

${ }^{3}$ Macro areas are defined by the Italian National Institute of Statistics (ISTAT) which groups Italian regions into 4 areas: North West (Lombardy, Piedmont, Liguria), North East (Veneto, Trentino Alto Adige, Friuli Venezia Giulia, Emilia Romagna), Centre (Lazio, Umbria, Marche, Tuscany), South and Islands (Campania, Apulia, Abruzzo, Molise, Basilicata, Calabria, Sicily, Sardinia).

${ }^{4}$ If merged with the data from a previous survey, the IXth survey plus AIDA reduces to a tiny sample of firms.
} 
innovative and non innovative firms. ${ }^{5}$ Innovative firms had introduced a product or process innovation (or both) in the three-year period considered by the survey (2001-2003). Non innovative firms declared to never introduce innovations in the period. This test is at first carried out without allowing for endogenous regime switching.

We perform the test by comparing the estimates of equation (4) on the two subgroups (unconstrained model) and on the whole sample (constrained model). The null hypothesis is that the constrained model is valid. The F-test when the firms are grouped as innovative and non innovative is $\mathrm{F}(31,7915)=15.99 \mathrm{p}$-value $=0.0$, thus rejecting the null. $\mathrm{P}$-values are reported in Table 4 and refer to the three innovation modes, depending on whether the group discriminant refers to whether the firm undertakes either product or process innovations, product innovation only, or process innovation only. The Chow test always rejects the null hypothesis, thus indicating that the partial correlation between age and the share of temporary workers, on one side, and the dependent variable on the other differs across the two groups of firms.

Consistently with the test results, we allow the parameters of interest of the experience variables to vary across groups, according to the specification equation (5):

$$
\begin{aligned}
\Delta_{2} \ln \left(\frac{Y}{L}\right)_{i t} & =\alpha \Delta_{2} \ln \left(\frac{K}{L}\right)_{i t}+\beta_{1} D_{1}+\beta_{2} D_{2}+\gamma_{1} \text { Age } e_{i} D_{1}+\gamma_{2} \text { Age }_{i} * D_{2}+\mu_{1}\left(\frac{\text { Temporary }}{L}\right)_{i t-2} * D_{1}+ \\
& +\mu_{2}\left(\frac{\text { Temporary }}{L}\right)_{i t-2} * D_{2}+\varepsilon_{i t}
\end{aligned}
$$

The dummies $D_{1}$ and $D_{2}$ identify the two groups of firms $\left(D_{1}=1\right.$ if the firm is innovative and $D_{2}=$ 1 if it is non innovative). $\mathrm{D}_{2}$ will be omitted in the regression because of collinearity. Notice that the innovation dummy captures the impact of technological progress on labor productivity as in a standard Cobb-Douglas production function approach.

In Table 4 we also report the Wald tests (and the relative $p$ values) of parameter instability for each parameter, when the null hypothesis is:

\footnotetext{
${ }^{5}$ In the robustness checks section we applies the Chow test also to $\alpha$, assuming that the growth rate of the capital-labor ratio differs across groups as well. In the benchmark model, we assume that the effect of $\mathrm{K} / \mathrm{L}$ on labor productivity does not differ across types of firms.
} 


$$
H_{0}:\left\{\begin{array}{l}
\gamma_{1}=\gamma_{2} \\
\lambda_{1}=\lambda_{2} \\
\mu_{1}=\mu_{2}
\end{array}\right.
$$

The third step forward considers the formation of the groups as endogenous. The idea is that firms introduce innovations because they are more productive, young or intensive at investing into R\&D activities or innovative capital, or maybe because they have more cash flows. The age profile of the board members and/or the share of temporary workers might be correlated to the innovativeness of the firms as well.

The new specification for labor productivity growth can be thought of as a standard case of switching regression model with endogenous switching (as explained firstly in Maddala 1983). We want to consistently estimate the parameters in two regimes: whether firms are innovative (regime $\mathrm{j}$ $=1$ ) or non innovative (regime $\mathrm{j}=2$ ) over the period of observation. The new model specification is the following.

$$
\left\{\begin{array}{l}
\Delta_{2} \ln \left(\frac{Y}{L}\right)_{i t}=\alpha \Delta_{2} \ln \left(\frac{K}{L}\right)_{i t}+\beta_{1}+\gamma_{1} \text { Age } e_{i}+\mu_{1}\left(\frac{\text { Temporary }}{L}\right)_{i t-2}+\varepsilon_{1 i t} \text { if innovative } \\
\Delta_{2} \ln \left(\frac{Y}{L}\right)_{i t}=\alpha \Delta_{2} \ln \left(\frac{K}{L}\right)_{i t}+\beta_{2}+\gamma_{2} \text { Age } e_{i}+\mu_{2}\left(\frac{\text { Temporary }}{L}\right)_{i t-2}+\varepsilon_{2 i t} \text { if noninnovativt }
\end{array}\right.
$$

The marginal distribution of the error terms $\varepsilon_{j i t} \mathrm{j}=1,2$ can be assumed normal with zero mean and constant variance $\sigma_{\mathrm{j}}{ }^{2}$. We shall modify this strong assumption in the robustness estimations. The conditional distribution of the error terms are instead different from zero, according to:

$$
\begin{aligned}
& \mathrm{E}\left(\varepsilon_{1 i t} \mid \text { innovative }\right) \neq 0 \\
& \mathrm{E}\left(\varepsilon_{2 i t} \mid \text { non innovative }\right) \neq 0
\end{aligned}
$$

This is because a criterion function determines whether a firm belongs to regime 1 or 2 , as in equation (7): ${ }^{6}$

$$
\left\{\begin{array}{c}
D_{1}=1 \text { if } \delta^{\prime} Z_{\text {it }}+\omega_{i t}>0 \\
D_{1}=0 \text { otherwise }
\end{array}\right.
$$

\footnotetext{
${ }^{6} \mathrm{D}_{1}=0 \Leftrightarrow D_{2}=1$, meaning that, if a firm has not introduced an innovation in 2001-2003, it is non innovative by definition.
} 
The criterion function depends on the Zs, namely variables correlated with the decision of introducing innovations, such as $\mathrm{R} \& \mathrm{D}$ expenditure at the beginning of the sample period and the other determinants of innovation, including age and the share of temporary workers.

To estimate the parameters $\delta^{\prime}$ we observe that the expected value $E\left(D_{1}\right)=P\left(D_{1}=1\right)=P\left(\delta^{\prime} Z_{i t}+\omega_{i t}>0\right)$ is the probability of being an innovative firm. If the error term $\omega_{i t}$ is assumed with $\mathrm{E}\left(\omega_{i t}\right)=0$ and $\mathrm{V}\left(\omega_{i t}\right)=1$ the (first stage) estimation method applied is the probit maximum likelihood.

Usually equation (6) is estimated separately for the two regimes, whose idiosyncratic errors are correlated with $\omega_{i t}$, according to the covariance matrix:

$$
\operatorname{Var}\left[\begin{array}{c}
\varepsilon_{1} \\
\varepsilon_{2} \\
\omega
\end{array}\right]=\left[\begin{array}{ccc}
\sigma_{1}^{2} & 0 & \sigma_{\varepsilon_{1} \omega} \\
0 & \sigma_{2}^{2} & \sigma_{\varepsilon_{2} \omega} \\
\sigma_{\varepsilon_{1} \omega} & \sigma_{\varepsilon_{2} \omega} & 1
\end{array}\right]
$$

In this case we need to introduce corrections for the error conditional mean as in (8) and (8'):

$$
\begin{aligned}
& \mathrm{E}\left(\varepsilon_{1 i t} \mid D_{1}=1\right)=\mathrm{E}\left(\sigma_{\varepsilon_{1} \omega} \omega_{i t} \mid \delta^{\prime} Z_{i t}+\omega_{i t}>0\right)=-\sigma_{\varepsilon_{1} \omega} \frac{\phi\left(\delta^{\prime} Z_{i t}\right)}{\Phi\left(\delta^{\prime} Z_{i t}\right)} \\
& \mathrm{E}\left(\varepsilon_{2 i t} \mid D_{2}=1\right)=\mathrm{E}\left(\sigma_{\varepsilon_{2} \omega} \omega_{i t} \mid \delta^{\prime} Z_{i t}+\omega_{i t} \leq 0\right)=\sigma_{\varepsilon_{2} \omega} \frac{\phi\left(\delta^{\prime} Z_{i t}\right)}{1-\Phi\left(\delta^{\prime} Z_{i t}\right)}
\end{aligned}
$$

where $\phi(\cdot)$ and $\Phi(\cdot)$ are, respectively, the standard normal density and cumulative distribution functions. To calculate (8) and (8') notice that we used the conditional distribution of $\varepsilon$ given $\omega$. This is normal with mean $\mathrm{E}\left(\varepsilon_{\mathrm{jit}} \mid \omega_{\mathrm{it}}\right)=\sigma_{\varepsilon \mathrm{j} \omega} \omega_{\mathrm{it}}$ and variance $\mathrm{V}\left(\varepsilon_{\mathrm{jit}} \mid \omega_{\mathrm{it}}\right)=\sigma_{\mathrm{j}}^{2}-\sigma_{\varepsilon j \omega}^{2}$. Given (6)-(8'), our specification becomes:

$$
\begin{cases}\Delta_{2} \ln \left(\frac{Y}{L}\right)_{i t}=\alpha \Delta_{2} \ln \left(\frac{K}{L}\right)_{i t}+\beta_{1}+\gamma_{1} \text { Age }+\mu_{1}\left(\frac{\text { Temporary }}{L}\right)_{i t-2}-\sigma_{\varepsilon_{1} \omega} \frac{\phi\left(\delta Z_{i t}\right)}{\Phi\left(\delta Z_{i t}\right)}+\mathrm{u}_{1 \mathrm{it}} & \text { if } \mathrm{D}_{1}=1 \\ \Delta_{2} \ln \left(\frac{Y}{L}\right)_{i t}=\alpha \Delta_{2} \ln \left(\frac{K}{L}\right)_{i t}+\beta_{2}+\gamma_{2} \text { Age }+\mu_{2}\left(\frac{\text { Temporary }}{L}\right)_{i t-2}+\sigma_{\varepsilon_{1} \omega} \frac{\phi\left(\delta Z_{i t}\right)}{1-\Phi\left(\delta Z_{i t}\right)}+\mathrm{u}_{2 \mathrm{it}} & \text { if } \mathrm{D}_{1}=0\end{cases}
$$

This system of equations can be estimated consistently with OLS (second stage) after substituting the estimate of $\delta ' Z$ in the correction terms (derived from first stage probit estimation). ${ }^{7}$

\footnotetext{
${ }^{7}$ Building on Maddala (1983) we could simplify equation (9) simultaneously, adding the correction term, i.e. the sum of $(8)+(8$ '), for the whole sample:
} 
We may also allow the parameter of the capital-labor ratio to vary across groups. If this is the case, the system of equations (9) may be written as:

$$
\begin{cases}\Delta_{2} \ln \left(\frac{Y}{L}\right)_{i t}=\alpha_{1} \Delta_{2} \ln \left(\frac{K}{L}\right)_{i t}+\beta_{1}+\gamma_{1} \text { Age }+\mu_{1}\left(\frac{\text { Temporar } \gamma)}{L}\right)_{i t-2}-\sigma_{\varepsilon_{1} \omega} \frac{\phi\left(\delta Z_{i t}\right)}{\Phi\left(\delta Z_{i t}\right)}+\mathrm{u}_{1 \mathrm{it}} & \text { if } \mathrm{D}_{1}=1 \\ \Delta_{2} \ln \left(\frac{Y}{L}\right)_{i t}=\alpha_{2} \Delta_{2} \ln \left(\frac{K}{L}\right)_{i t}+\beta_{2}+\gamma_{2} \text { Age }+\mu_{2}\left(\frac{\text { Temporar } \gamma}{L}\right)_{i t-2}+\sigma_{\varepsilon_{1} \omega} \frac{\phi\left(\delta Z_{i t}\right)}{1-\Phi\left(\delta Z_{i t}\right)}+\mathrm{u}_{2 \mathrm{it}} & \text { if } \mathrm{D}_{1}=0\end{cases}
$$

Clearly, if none of the parameters varies across groups, equation (9) reduces to the simple original form (4):

$$
\Delta_{2} \ln \left(\frac{Y}{L}\right)_{i t}=\alpha \Delta_{2} \ln \left(\frac{K}{L}\right)_{i t}+\beta+\gamma \operatorname{Age}_{i}+\mu\left(\frac{\text { Temporary }}{L}\right)_{i t-2}+\varepsilon_{i t}
$$

This is the constrained equation (constraint being equal parameters in all groups) used in the former Chow test. Leaving aside the potential endogeneity of the capital-labor ratio, the problem of endogenous group formation in the latter case disappears altogether.

As to the potential endogeneity of the capital stock, we assume that capital accumulation depends on past investment intensities and initial levels of capital/labor ratio, conditional on size, sector and group of the firm, whether or not it has introduced innovations, and on firm age. Because of this, we

$$
\begin{aligned}
& \mathrm{E}\left(\Delta_{2} \ln \left(\frac{Y}{L}\right)_{i t}\right)=\mathrm{E}\left(\Delta_{2} \ln \left(\frac{Y}{L}\right)_{i t} \mid D_{1}=1\right) * P\left(D_{1}=1\right)+\mathrm{E}\left(\Delta_{2} \ln \left(\frac{Y}{L}\right)_{i t} \mid D_{1}=0\right) * P\left(D_{1}=0\right) \\
& =\alpha \Delta_{2} \ln \left(\frac{K}{L}\right)_{i t}+\left\{\beta_{1}+\gamma_{1} \text { Age } e_{i}+\mu_{1}\left(\frac{\text { Temporary }}{L}\right)_{i t-2}-\sigma_{\mathcal{E}_{1}} \omega \frac{\phi\left(\delta^{\prime} Z_{i t}\right)}{\Phi\left(\delta^{\prime} Z_{i t}\right)}\right\} \Phi\left(\delta^{\prime} Z_{i t}\right)+ \\
& +\left\{\beta_{2}+\gamma_{2} \text { Age } e_{i}+\mu_{2}\left(\frac{\text { Temporary }}{L}\right)_{i t-2}+\sigma_{\mathcal{E}_{2}} \omega \frac{\phi\left(\delta^{\prime} Z_{i t}\right)}{1-\Phi\left(\delta^{\prime} Z_{i t}\right)}\right\}\left[1-\Phi\left(\delta^{\prime} Z_{i t}\right)\right]
\end{aligned}
$$

Rearranging terms, we would obtain an estimable specification which allows to perform Wald tests of parameters instability. When the coefficients of the interactions are equal to zero, this procedure is a convenient way to impose cross-equation restrictions on the two-regime specification:

$$
\begin{aligned}
& \Delta_{2} \ln \left(\frac{Y}{L}\right)_{i t}=\alpha \Delta_{2} \ln \left(\frac{K}{L}\right)_{i t}+\beta_{2}+\gamma_{2} \text { Age }_{i}+\mu_{2}\left(\frac{\text { Temporary }}{L}\right)_{i t-2}+\left(\beta_{1}-\beta_{2}\right) \Phi\left(\hat{\delta}^{\prime} Z_{i t}\right)+ \\
& +\left(\gamma_{1}-\gamma_{2}\right) A g e_{i} \Phi\left(\hat{\delta} Z_{i t}\right)+\left(\mu_{1}-\mu_{2}\right)\left(\frac{\text { Temporary }}{L}\right)_{i t-2} \Phi\left(\hat{\delta} Z_{i t}\right)++\phi\left(\hat{\delta} Z_{i t}\right)\left(\sigma_{\mathcal{E}_{2}} \omega-\sigma_{\varepsilon_{1}} \omega\right)+\xi_{i t}
\end{aligned}
$$

where $\xi_{\text {it }}$ has a standard normal distribution. 
will use 2SLS-IV method for the equation systems (9) and (9') at the second stage as well, where the growth rate of the capital-labor ratio is instrumented.

\section{The dataset}

We collected balance sheet data for a representative sample of Italian manufacturing firms and their board characteristics in the period 2001-2003 from two sources of data. Information about employment characteristics, innovation activity and R\&D investment at the firm level come from the IX ${ }^{\text {th }}$ Survey on Manufacturing Firms by the Italian bank Capitalia-Unicredit.

This survey has been run in 2004 through questionnaires distributed to 4177 firms. The questionnaires inquire about location, legal form, group, sales, investments, R\&D investments, innovation activity, exports, labor force characteristics, financial status and incentives, balance sheets. Most of the quantitative information relates to the previous three years since the time of the survey, separately. Some qualitative answers, instead, are related to the whole three-year period, i.e. innovation activity.

Information about balance sheets and age of the board members come instead from the AIDA database. ${ }^{8}$ AIDA is updated every week but maintains balance sheet data for the previous years as well. Thus we extracted balance sheet items over the 2001-2003 spanning to check and correct for inconsistencies between the two sources. Incidentally, our chosen sub-period - the years between 2001 and 2003 - happens to be a period during which Italy's productivity shortfall has been particularly severe.

While we can extract balance sheet from AIDA in the years of interest to match the two sources, the database registers just the latest board composition, which means that we access information about board members of existing firms on December 31, 2007. We know the year at which the person was

\footnotetext{
${ }^{8}$ AIDA is managed by Bureau Van Dijk. It collects balance sheets, proprietary shares, firm characteristics and board characteristics on about 250000 Italian firms. We accessed the data on firms with at least $€ 800.000$ gross sales as of 31 December 2007.
} 
nominated but the duration of the service is practically unknown, and her/his function is scarcely available. Thus we take the board composition as if it was present in 2001-2003 as well. For each member with available data, we calculate her/his age at the time of the nomination within the board, as well as the age in 2001, 2002 and 2003. For each firm we have calculated an average age of the board. We excluded from the dataset those firms whose board name appeared to be another company, not a physical person. We also excluded those firms whose board members' appointment appears to have occurred before their birth dates.

Firms in the Capitalia-Unicredit dataset (with information relative to the 2001-2003 period) also present in 2007 to match AIDA information are 3562 (that is $85.3 \%$ of the sample). Firm-individual observations are 21081. We first test for potential sample selection of these firms, in terms of age, size, location and sector of production (younger, bigger or particular sectors could have a higher survival rate, higher productivity or innovation capacity). The discussion of the potential selection bias is placed in the Appendix section of this paper. The data then need a cleaning procedure because of inconsistencies between birth dates and appointment dates of the individual board members, implausible firm age, non-individual board members, missing values. Only 7977 (about $40 \%$ of total observations) distributed in 1042 firms contain sensible information on birth and service dates and other variables, which finally becomes our longitudinal or "quasi"-panel dataset with firms as units and board members as the longitudinal dimension, in the years 2001-2003. 
Table 2. Descriptive statistics of the main variables of interest.

\begin{tabular}{|c|c|c|c|c|c|}
\hline Fixed characteristics $^{\mathrm{o}, b}$ & Firms & Yes & No & & \\
\hline Product & 1042 & 51.1 & 48.9 & & \\
\hline Process & 1042 & 55.2 & 44.8 & & \\
\hline Either Product or Process & 1042 & 73.7 & 26.3 & & \\
\hline R\&D spending (yes/no) & 1042 & 63.3 & 36.7 & & \\
\hline Group & 1042 & 49.3 & 50.7 & & \\
\hline High-tech & 1042 & 33.2 & 66.8 & & \\
\hline Variables of interest & & Mean & St.D. & Min & Max \\
\hline Production per worker ${ }^{\epsilon}$ & 1042 & 311.67 & 268.42 & 16.54 & 2384.78 \\
\hline$\Delta_{2} \log (\text { Production } / \mathrm{L})^{\mathrm{b}}$ & 1042 & 2.11 & 30.45 & -294.86 & 293.71 \\
\hline Capital Stock per worker ${ }^{€}$ & 1042 & 64.45 & 67.63 & 0.193 & 652.99 \\
\hline$\Delta_{2} \log (\text { Capital Stock } / \mathrm{L})^{\mathrm{b}}$ & 1042 & 17.60 & 42.03 & -365.23 & 348.57 \\
\hline Total Workers ${ }^{\mathrm{a}}(\mathrm{L})$ & 1042 & 208.7 & 559.5 & 6 & 12199 \\
\hline Temporary Workers Rate ${ }^{\mathrm{a}, \mathrm{b}}$ & 1042 & 4.21 & 12.43 & 0 & 100 \\
\hline R\&D Workers ${ }^{\mathrm{a}}$ & 1020 & 7.47 & 34.08 & 0 & 755 \\
\hline R\&D investment per worker ${ }^{\epsilon, a}$ & 563 & 3.14 & 5.44 & 0 & 77.672 \\
\hline R\&D intensity (Production) $)^{a, b}$ & 563 & 1.64 & 3.83 & 0 & 57.6 \\
\hline Investment intensity (Production) $)^{\mathrm{a}, \mathrm{b}}$ & 1042 & 3.86 & 5.18 & 0 & 34.4 \\
\hline Cash flow per worker ${ }^{\epsilon, a}$ & 1042 & 23.089 & 37.769 & -86.603 & 736.728 \\
\hline Average Board age (years) & 1042 & 49.6 & 6.45 & 20 & 77 \\
\hline Age of the firm ${ }^{\mathrm{a}}$ (years) & 1033 & 26.9 & 20.0 & 0 & 172 \\
\hline
\end{tabular}

Note: Dummy variables statistics are expressed in fraction. ${ }^{a}$ measured in $2001{ }^{\circ}$ referred to $2001-2003$ period, ${ }^{b}$ in percentage points, ${ }^{€}$ in thousand euros.

Table 3. Firm size and area distribution in the final sample of firms.

\begin{tabular}{|l|l|l|l|l|l|l|l|}
\hline & Small & Medium & Large & North West & North East & Centre & South \\
\hline Freq & 206 & 658 & 178 & 376 & 354 & 160 & 152 \\
\hline$\%$ & 19.7 & 63.2 & 17.1 & 36.1 & 34.0 & 15.3 & 14.6 \\
\hline
\end{tabular}

\section{Results}

\subsection{Exogenous group formation}

If the decision to innovate (and hence group formation) is taken for granted, equation (5) can be estimated through OLS. 
Table 4. OLS Estimates of labor productivity growth rates (in percentage points).

\begin{tabular}{|c|c|c|c|c|c|c|}
\hline \multirow{2}{*}{$\begin{array}{l}\text { Dependent variable } \\
\Delta_{2} \ln \frac{Y_{i t}}{L_{i t}}\end{array}$} & \multicolumn{2}{|c|}{ Any innovation } & \multicolumn{2}{|c|}{ Product } & \multicolumn{2}{|c|}{ Process } \\
\hline & Coefficient & $\begin{array}{l}\text { Robust } \\
\text { Std. Err. }\end{array}$ & Coefficient & $\begin{array}{l}\text { Robust } \\
\text { Std. Err. }\end{array}$ & Coefficient & $\begin{array}{l}\text { Robust } \\
\text { Std. Err. }\end{array}$ \\
\hline Innovative firms & $15.12 * *$ & 7.094 & 2.588 & 5.954 & $17.24^{* * *}$ & 6.006 \\
\hline$\Delta_{2} \ln \frac{K_{i t}}{L_{i t}} *$ Innov & $0.2587 * * *$ & 0.008 & $0.292^{* * *}$ & 0.009 & $0.304^{* * *}$ & 0.009 \\
\hline$\Delta_{2} \ln \frac{K_{i t}}{L_{i t}} *$ non_Innov & 0.01 & 0.015 & $0.069^{* * *}$ & 0.011 & 0.019 & 0.012 \\
\hline Age*Innov & $-0.283 * * *$ & 0.069 & $-0.286^{* * *}$ & 0.085 & $-0.366^{* * *}$ & 0.078 \\
\hline Age*non_Innov & 0.091 & 0.125 & -0.109 & 0.084 & 0.066 & 0.091 \\
\hline Temporary*Innov & $-0.095 * * *$ & 0.035 & $-0.073^{*}$ & 0.041 & $-0.106^{* * *}$ & 0.039 \\
\hline Temporary*non_Innov & $-0.199 * * *$ & 0.046 & $-0.213^{* * * *}$ & 0.037 & $-0.197^{* * *}$ & 0.039 \\
\hline Large & $-1.94^{*}$ & 1.113 & $-1.894^{*}$ & 1.108 & -1.081 & 1.096 \\
\hline Medium & $-5.74^{* * *}$ & 0.876 & $-5.965^{* *}$ & 0.871 & $-4.970^{*}$ & 0.864 \\
\hline Group & $2.86^{* * *}$ & 0.680 & $3.199^{* * *}$ & 0.679 & $2.48^{* * *}$ & 0.675 \\
\hline Constant & 2.61 & 10.19 & 14.019 & 8.799 & 3.637 & 9.216 \\
\hline Industry dummies & yes & & yes & & yes & \\
\hline Region dummies & yes & & yes & & yes & \\
\hline \multicolumn{7}{|c|}{ Wald test for equality of coefficients between Innovative and non Innovative } \\
\hline Capital-labor ratio & {$[0.000]$} & & {$[0.000]$} & & {$[0.000]$} & \\
\hline Age & {$[0.0085]$} & & {$[0.138]$} & & {$[0.0003]$} & \\
\hline Share of temporary & [0.069] & & {$[0.011]$} & & [0.0946] & \\
\hline Chow test F & {$[0.000]$} & & {$[0.000]$} & & {$[0.000]$} & \\
\hline $\operatorname{Adj} R^{2}$ & 0.154 & & 0.157 & & 0.171 & \\
\hline $\mathrm{N}$ & 7977 & & 7977 & & 7977 & \\
\hline
\end{tabular}

Note: $* 10 \%, * * 5 \%, * * * 1 \%$ level of significance, p-values in brackets. Size, areas, industry and group dummies are included in all regressions.

Table 4 shows the OLS coefficients and robust standard errors of the estimates of labor productivity growth rates (two-year rates) on our variables of interest, interacted with the group dummies. "Innov" refers to the group of firms introducing an innovation in 2001-2003, while "non_Innov" refers to the group of the non innovative firms. Column 1 and 2 refer to firms which have introduced any - hence either product or process - innovation. Column 3 and 4 refer to firms which have introduced product innovation only and column 5 and 6 refer to firms having introduced process innovation only. All the regressions include standard control variables such as size, geographical areas, industry dummies, as well as the dummy that takes a value of one for firms 
belonging to a group and a value of zero for those not belonging to any group, which, in previous work (see for instance Parisi, Schiantarelli and Sembenelli, 2006), has been shown to be a statistically significant correlate of firms' productivity performance.

The innovation dummy reports a coefficient of 15.12 with $5 \%$ statistical significance. This means that there exists a significant drift of 15.1 percentage points for productivity growth for the Italian innovative firms, even in the years considered. This is particularly true for those firms introducing process innovation $(17.2 \%)$, while the drift is nearly not significant for those firms introducing product innovation.

For the group of innovative firms, irrespectively of how innovation is defined, the estimate of the age coefficient is negative and statistically significant. The point-wise estimates indicate that an increase in the average age of the board members of one year translates into lower productivity growth of some $0.28-0.37$ percentage points. As to the non innovative group, the effect is zero: having a younger board of governance on average does not spur productivity growth for the noninnovative firms. The semi-elasticity of age for the whole sample is instead not significantly different from zero. In order to capture the partial correlation of age and productivity growth it is thus crucial to distinguish between innovative and non-innovative categories of firms.

The coefficient estimate for the temporary workers share is instead statistically significant and negative both for the innovative and the non-innovative group, with point-wise estimates around .10 for the innovative and around -.20 for the non innovative firms. The Wald test for equality of parameters in the case of the temporary workers share has a p-value in the 5\%-10\% range, meaning that it is not clear whether the coefficients are to be considered different or not across groups. We can think that a firm endowed with a high share of temporary workers always exhibits lower productivity growth.

Finally, the capital-labor ratio coefficient is usually significant and positive for the innovative firms, its point-wise estimate is almost three times bigger (.26) than that of non-innovative firms (around .07 in the case of product innovative firms). The three Wald tests of parameter stability always 
reject the null. The imprecise estimates of the capital per worker growth in the non innovative group might be due to its potential endogeneity.

To confirm our results, Table 4 reports p-values of the Wald tests of parameter instability for the $\mathrm{H}_{0}$ hypotheses:

$$
H_{0}:\left\{\begin{array}{l}
\gamma_{1}=\gamma_{2} \\
\lambda_{1}=\lambda_{2} \\
\mu_{1}=\mu_{2}
\end{array}\right.
$$

The test for age and the capital-labor ratio coefficients rejects the null of equal parameters ( $p$-value of the test is equal to zero). In general the three Wald tests reveal that the constrained model has to be rejected.

\subsection{Endogenous innovation decision}

Table 5 and 6 show the results from the two-stage method of estimation of the parameters in (7) and (9'), which take into account the endogenous formation of the two groups. The two-stage analysis allows us to perfect our understanding of the relation between our variables of interest and productivity growth.

Table 5 shows the estimates of the first stage, namely the decision to innovate. The probit estimations of Table 5 are used as a first stage in the switching regression with endogenous switching (eq. (7)). The probit results for product innovation appear in column 3 and 4 and those for process innovation appear in column 5 and 6 . These latter regressions are useful to understand the importance of the different instruments in determining innovation decisions. The given set of instruments predicts much better the probability to undertake a product innovation than a process innovation. Moreover, engaging in $R \& D$ activity and hiring $R \& D$ workers has a much stronger effect on the probability of undertaking product innovation than on the one of process innovation. In contrast, per-worker current cash flow seems to be an important pre-condition for introducing 
process innovations. Both large and medium-sized firms appear to be more often innovative that small firms.

As far as our main variables of interest are concerned, the share of temporary workers does not appear to significantly affect the decision to innovate if we split innovations between product and process, while the average age of board members does it already at this first stage.

Table 5. Probit Maximum Likelihood for Innovation dummies (first stage).

\begin{tabular}{|l|l|l|l|l|l|l|}
\hline \multirow{2}{*}{ Probit ML } & \multicolumn{2}{|c|}{ Innovation } & \multicolumn{2}{c|}{ Product } & \multicolumn{2}{c|}{ Process } \\
\cline { 2 - 7 } & Coeff & $\begin{array}{l}\text { Robust } \\
\text { Std. Err. }\end{array}$ & Coeff & $\begin{array}{l}\text { Robust } \\
\text { Std. Err. }\end{array}$ & Coeff & $\begin{array}{l}\text { Robust } \\
\text { Std. Err. }\end{array}$ \\
\hline R\&D: yes & $0.687^{* * *}$ & .0431 & $.811^{* * *}$ & .041 & $.329^{* * *}$ & .039 \\
\hline R\&D workers $\mathrm{t}_{-1}$ & $0.250^{* * *}$ & .0221 & $.316^{* * *}$ & .018 & $.118^{* * *}$ & .016 \\
\hline Cash flow $\mathrm{t}_{2} 2$ & $0.0017^{* * *}$ & .0006 & .0006 & .0004 & $.0015^{* * *}$ & .0004 \\
\hline Large & $0.260^{* * *}$ & .0594 & $.211^{* * *}$ & .056 & $.250^{* * *}$ & .053 \\
\hline Medium & $0.297^{* * *}$ & .0424 & $.138^{* * *}$ & .042 & $.254^{* * *}$ & .039 \\
\hline Temporary workers & $-0.003^{* *}$ & .0014 & .0006 & .0014 & -.0019 & .0013 \\
\hline Age of board members & $-0.012^{* * *}$ & .0031 & $-.008^{* * *}$ & .0029 & $-.017^{* * *}$ & .0027 \\
\hline Constant & $0.439^{* * *}$ & .1576 & $-.552^{* * *}$ & .149 & $.465^{* * *}$ & .141 \\
\hline Pseudo-R 2 & 0.153 & & 0.2014 & & 0.047 & \\
\hline $\mathrm{N}$ & 7773 & & 7773 & & 7773 & \\
\hline
\end{tabular}

Table 6 shows the estimates of the second stage switching regression: the Maddala method with OLS on eq. (9') and a 2SLS-IV method to take into account the endogeneity of the growth rate of capital stock per worker. ${ }^{9}$ The instruments used for the growth rate of the capital stock prediction are the initial level of the capital/labor ratio, age of the firm at the beginning of the sample period, investment intensity at the beginning of the sample period, size, area, sector and group dummies.

Table 6 indicates that the method of estimation does not matter very much: the estimated coefficients for innovative firms are in fact very similar when using OLS and 2SLS; the same applies to the sample of non-innovative firms. It should also be noticed that the switching regression correction is only positive and significant for the innovative firms. The estimated regressions for the innovative firms tend to exhibit a larger $\mathrm{R}^{2}$ than for the non-innovative firms (respectively 0.22 in

\footnotetext{
${ }^{9}$ We run similar regressions of equations derived in Note 8 , which allows to test for parameters equality between the two regimes. The results confirm the presence of significant differences in the estimates of the coefficients, in particular as far as age and the rate of temporary workers are concerned, between the two regimes. The table with these other regressions are available upon requests.
} 
the OLS case and .21 in the 2SLS case vis-à-vis .10 for their correspondent regressions). The Sargan tests for over-identifying restrictions cannot reject the hypothesis of validity of instruments only at the $5 \%$ level, with a p-value of .064 for the innovative firms and .72 for the non-innovative ones.

The impact of mean age of the board members on productivity growth is negative and statistically significant $\left(\gamma_{1, \mathrm{OLS}}=-0.31, \gamma_{1,2 \mathrm{SLS}}=-0.31\right)$ for innovative firms and positive and non significant $\left(\gamma_{2, \mathrm{OLS}}=\gamma_{2,2 \mathrm{SLS}}=.06\right)$ for the non-innovative firms. Hence the statistical significance stays there and the point-wise estimates are in the same ballpark (perhaps higher for the innovative firms) as the OLS results previously shown in Table 4.

Again replicating the same pattern of results as in Table 4, the estimates for the capital share are almost three times higher for innovative firms than for non-innovative firms. The OLS method appears slightly overestimating $\alpha_{1, \mathrm{OLS}}=0.256$ and 0.087 , respectively, for innovative and noninnovative, while $\alpha_{1,2 \mathrm{SLS}}=0.20$ and remains equal to 0.085 for the non innovative when the capital stock is instrumented with the 2SLS method.

The impact of the share of temporary workers does not also differ significantly across estimation methods but they differ in significance across categories of firms. The share of temporary workers affects negatively productivity growth at the second stage for innovative firms (with coefficients of some negative $.11-.12$, very similar to those found in Table 4), and it is -0.27 for the non innovative firms. This result replicates that of Table 4, where the corresponding coefficients were slightly smaller. 
Table 6. Second stage results for system (9'), OLS and 2SLS.

\begin{tabular}{|c|c|c|c|c|c|c|c|c|c|}
\hline \multirow{2}{*}{$\begin{array}{l}\text { Dependent } \\
\Delta_{2} \ln \frac{Y_{i t}}{L_{i t}}\end{array}$} & \multicolumn{2}{|l|}{ OLS } & \multicolumn{2}{|l|}{ 2SLS } & & \multicolumn{2}{|l|}{ OLS } & \multicolumn{2}{|l|}{ 2SLS } \\
\hline & Coeff & $\begin{array}{l}\text { Robust } \\
\text { St.E. }\end{array}$ & Coeff & $\begin{array}{l}\text { Robust } \\
\text { St.E. }\end{array}$ & & Coeff & $\begin{array}{l}\text { Robust } \\
\text { St.E. }\end{array}$ & Coeff & $\begin{array}{l}\text { Robust } \\
\text { St.E. }\end{array}$ \\
\hline & \multicolumn{4}{|c|}{ Innovative firms } & & \multicolumn{4}{|c|}{ Non Innovative firms } \\
\hline $\boldsymbol{\alpha}_{1}(\mathrm{~K} / \mathrm{L}$ ratio $)$ & $0.256^{* * *}$ & 0.0265 & $0.199^{* * *}$ & 0.0302 & $\boldsymbol{\alpha}_{2}$ & $0.087^{* * *}$ & 0.0212 & $0.085^{* * *}$ & 0.0239 \\
\hline$\beta_{1}$ (constant) & $20.164^{* * *}$ & 3.204 & $20.46^{* * *}$ & 3.146 & $\beta_{2}$ & -6.68 & 7.755 & -6.67 & 7.698 \\
\hline$\gamma_{1}$ (age) & $-0.307^{* * *}$ & 0.0465 & $-0.313^{* * *}$ & 0.0453 & $\gamma_{2}$ & 0.061 & 0.1375 & 0.061 & 0.1366 \\
\hline $\begin{array}{l}\mu_{1} \text { (temporary } \\
\text { workers) }\end{array}$ & $-0.114^{* * *}$ & 0.023 & $-0.123^{* * *}$ & 0.0234 & $\mu_{2}$ & $-0.273^{* *}$ & 0.120 & $-0.272^{* *}$ & 0.1194 \\
\hline$-\sigma_{\varepsilon 1 \omega}$ & $2.597^{*}$ & 1.526 & $3.659^{* *}$ & 1.528 & $\sigma_{\varepsilon 2 \omega}$ & -1.557 & 3.152 & -1.545 & 3.1343 \\
\hline $\mathbf{R}^{2}$ & 0.215 & & 0.099 & & $\mathbf{R}^{2}$ & 0.208 & & 0.099 & \\
\hline Sargan test & & & $\begin{array}{l}3.429 \\
{[0.064]}\end{array}$ & & & & & $\begin{array}{l}.413 \\
{[0.520]}\end{array}$ & \\
\hline $\mathbf{N}$ & 5859 & & 5859 & & $\mathbf{N}$ & 1914 & & 1914 & \\
\hline & & & & & & & & & \\
\hline
\end{tabular}

Note. All regressions include size, sector, area and group dummies. The first stage refers to column 1 and 2 of

Table 5. The 2SLS method instruments the growth rate of the capital stock per worker with the lagged $\mathrm{K} / \mathrm{L}$ in levels and the lagged investment intensity.

As a robustness check we replicate the estimates of equation (4) for the sub-sample of managers who are supposed to take decisions within the board. We select those firms whose board contains competence-specific managers, who are supposed to influence the decision to introduce innovations in the firm, eventually. The sign and size of the main coefficients are confirmed. We omit reporting them here for brevity.

We finally implement the Maximum Likelihood Endogenous Switching model which allows us to obtain consistent and efficient estimates. 
Following the method suggested by Lokshin and Sajaia (2004) we estimate the equation system (9') first by including the growth rate of the capital stock as it is (analogously to the OLS method in Table 6), second by substituting the variable with its predicted value obtained through a first-stage regression with instruments (analogously to the 2SLS method used in Table 6). The results of the ML Endogenous Switching Model are shown in Table 7 below.

The results for innovative firms largely confirm those of Table 6 . The estimated share of the capital stock is equal to 0.196 when the capital stock is predicted. The parameters for mean age are estimated to be equal to -0.40 (overestimating with respect to OLS and 2SLS). The temporary worker share coefficient is higher both in ML and ML predicted (-0.19 and -0.22 respectively). The value of $\rho_{1}$ greater than zero means that the correlation between the residuals of the second-stage equation and the selection equation is positive. This means that an innovative firm does better in increasing productivity than a firm which randomly chooses to be in either regime.

The capital share for non innovative firms is zero both with ML and with ML predicted. This value is similar to the OLS result of Table 4.

Our estimates also indicate that the impact of average board age for non innovative firms is zero. This result is the same as that of Table 6, where the 2SLS coefficient is zero as well.

The impact of the share of temporary workers is instead negative and significant $\left(\mu_{2, \mathrm{ML}} \cong \mu_{2, \mathrm{MLpred}}=\right.$ -0.24). Finally, the correlation between selecting the regime and the second-stage equation is zero. The Wald test of independence across the equations (8) and (8') rejects the null of independence. Together with the positive and statistically significant Mills ratios, this means that the error correction-switching method is appropriate. 
Table 7. Second stage results for system (9'), Maximum Likelihood efficient method.

\begin{tabular}{|c|c|c|c|c|c|c|c|c|c|}
\hline \multirow{2}{*}{$\begin{array}{l}\text { Dependent } \\
\Delta_{2} \ln \frac{Y_{i t}}{L_{i t}}\end{array}$} & \multicolumn{2}{|l|}{ ML } & \multicolumn{2}{|c|}{ ML (predict $\hat{k})$} & & \multicolumn{2}{|l|}{ ML } & \multicolumn{2}{|c|}{ ML $(\operatorname{predict} \hat{k})$} \\
\hline & Coeff & $\begin{array}{l}\text { Robust } \\
\text { St. E. }\end{array}$ & Coeff & $\begin{array}{l}\text { Robust } \\
\text { Std. } \\
\text { Err. }\end{array}$ & & Coeff & $\begin{array}{l}\text { Robust } \\
\text { St. E. }\end{array}$ & Coeff & $\begin{array}{l}\text { Robust } \\
\text { St. E. }\end{array}$ \\
\hline & \multicolumn{4}{|c|}{ Innovative firms } & & \multicolumn{4}{|c|}{ Non Innovative firms } \\
\hline$\alpha_{1}$ & $.2588 * * *$ & .0244 & $.1967 * * *$ & .0382 & $\alpha_{2}$ & .0199 & .0195 & -.0004 & .0252 \\
\hline$\beta_{1}$ & $17.00 * * *$ & 3.343 & $18.17 * * *$ & 3.381 & $\beta_{2}$ & -6.658 & 10.85 & -6.414 & 10.023 \\
\hline$\gamma_{1}$ & $-.4028 * * *$ & .056 & $-.3862 * * *$ & .0591 & $\gamma_{2}$ & -.0105 & .1473 & -.0051 & .1462 \\
\hline$\mu_{1}$ & $-.1878 * * *$ & .0288 & $-.2172 * * *$ & .0308 & $\mu_{2}$ & $-.242 * *$ & .1174 & $-.2369 * *$ & .1167 \\
\hline$\sigma_{1}$ & $28.719 * * *$ & .8895 & $30.51 * * *$ & 1.096 & $\sigma_{2}$ & $29.941 * * *$ & .2622 & $29.93 * * *$ & .1986 \\
\hline$\rho_{1}$ & .6917 & .0936 & .6421 & .1211 & $\rho_{2}$ & .1126 & .1385 & .1039 & .1179 \\
\hline Mills ratio & $.4439 * *$ & .2767 & $.444 * *$ & .2821 & & $1.364 * * *$ & .5181 & $1.368^{* * *}$ & .5282 \\
\hline Condition & \multicolumn{2}{|c|}{ Exogenous K } & \multicolumn{2}{|c|}{ Endogenous K } & & & & & \\
\hline $\begin{array}{l}\text { Wald } \\
\chi^{2}(1)\end{array}$ & $\begin{array}{l}22.86 \\
{[0.000]}\end{array}$ & & $\begin{array}{l}13.95 \\
{[0.000]}\end{array}$ & & & & & & \\
\hline P(Inno) & .7356 & .1785 & .735 & .1816 & & & & & \\
\hline $\mathbf{N}$ & 7773 & & 7773 & & & & & & \\
\hline
\end{tabular}

Note. All regressions include size, area and sector dummies. Columns 3 and 4 show ML with predicted value of the growth rate of capital stock for innovative firms. Columns 7 and 8 replicate ML with predicted value for the non innovative cluster. Wald Chi-square test is testing for the independence of the residuals in system (8). $\mathrm{P}(\mathrm{Inno})$ is the predicted probability of being in the innovative regime in the first stage.

\section{Conclusions}

In this paper we exploited data from a sample of some eight thousands innovative and noninnovative firm-observations to describe the pattern of correlation between experience, innovation and productivity growth during the recent period of serious productivity slowdown in the Italian 
economy. Our results seem to indicate that both workers' and managerial experience matter for productivity growth.

As to managerial age, definite patterns of correlation are present once the whole sample is split into innovative and non-innovative clusters. Age, in particular - a measure of overall experience - in the labor market appears to be (positively correlated or) uncorrelated with productivity growth in noninnovative firms, while it is robustly negatively correlated with productivity growth in the sample of innovative firms. Results are also strongly statistically significant for our other variable of interest: the share of temporary workers is in most cases negatively correlated with productivity growth. This result seems to differ across groups in absolute value, being more important for non innovative firms.

The cross-sectional statistical analysis of long-differences based on firm-averaged data is not problem-free. A big issue is potential reverse causation. The statistical relations we intend to analyze posit that (say) age is the independent variable and productivity the dependent variable. But cross-section data as such (be they observed at a given point in time or averaged over time) may only indicate correlation, not causation. Therefore, if the estimated coefficient linking age and productivity is negative, this may not indicate that the firms where aged managers are employed are less productive. Rather, the negative correlation may simply signal that older managers tend to stay longer in less productive and older firms, featuring outdated machines and methods of production, probably because they managed to put in place successful "relations", while new, innovative and high-productivity plants may be more often matched to young and brilliant managers. If this is the case, we would be wrongly interpreting what causes what, attributing to age a causal influence on plant productivity, which may go the other way around. This is why we implement our 2SLS specification. Our expectation is that by choosing predetermined instruments, which also include age of the firm, we are lessening the simultaneity problems.

Surely, a lot of unobserved heterogeneity in plant productivity is still there in the data even once we have augmented the list of productivity determinants with dummies and other control variables. Yet 
the problem of interpreting the statistical results from cross-sectional estimates arises if and only if the unobserved (therefore unmeasured) firm variables are correlated with the included explanatory variables. For example, if managerial ability - a typically unobserved firm variable - were unrelated to the age of managers, then leaving it out of the empirical analysis would not be a major problem. This may or may not be the case though. If managerial ability is not observed and therefore omitted from the analysis but it turns out to be correlated with some included variable such as the age of managers, its effect may be picked up by the negative estimated relation between high-age managers and productivity. We would be misperceiving the effect of managerial ability on productivity as if it were the causal effect of age on productivity. To tackle this problem, we control for a few dummy variables that capture some, though presumably not all, of the unobserved determinants of firm productivity.

\section{References}

Autor, David H., Frank Levy, and Richard J. Murnane (2003): “The Skill Content of Recent Technological Change: An Empirical Exploration", Quarterly Journal of Economics, Vol. 118, No. 4, pp. 1279-1333.

Bandiera, Oriana, Luigi Guiso, Andrea Prat and Raffaella Sadun (2008): "Italian managers: fidelity or performance?" Report presented at the Annual Rodolfo De Benedetti Foundation Conference "The ruling class", September.

Brown, James R., Steven M. Fazzari, and Bruce C. Petersen (2009): "Financing Innovation and Growth: Cash Flow, External Equity, and the 1990s R\&D Boom”, Journal of Finance, Vol. 64, No. 1, pp.151-185.

Capitalia-Unicredit (2004): IX ${ }^{\text {th }}$ Survey on Manufacturing Firms.

Comin, Diego and Bart Hobijn (2009): "Lobbies and Technology Diffusion”, Review of Economics and Statistics, Vol. 91, No. 2, pp. 229-244. 
Crépon, Bruno, Emmanuel Duguet and Jacques Mairesse (1998): "Research, Innovation and Productivity: an Econometric Analysis at the Firm Level”, National Bureau of Economic Research, Inc, NBER Working Paper 6696.

Daveri, Francesco and Cecilia Jona Lasinio (2005): "Italy's decline: getting the facts right", Giornale degli Economisti ed Annali di Economia, Vol. 64, No. 4, pp. 365-410.

Daveri, Francesco and Mika Maliranta (2007): “Age, seniority and labor costs: lessons from the Finnish IT revolution", Economic Policy, Vol. 22, No. 49, pp.117-175.

Galenson, David W. (2007): “Artists and the Market: From Leonardo and Titian to Andy Warhol and Damien Hirst", National Bureau of Economic Research, Inc, NBER Working Papers 13377.

Galenson, David W. (2005): "Who Are the Greatest Living Artists? The View from the Auction Market”, National Bureau of Economic Research, Inc, NBER Working Papers 11644.

Galenson, David W. (2003): “The Life Cycles of Modern Artists: Theory, Measurement, and Implications”, National Bureau of Economic Research, Inc, NBER Working Papers 9539.

Geroski, Paul A. (2000): "Entry, Innovation and Productivity Growth", in Innovation, evolution of industry and economic growth. Volume 2, pp. 315-321, Elgar Reference Collection, International Library of Critical Writings in Economics, Vol. 118.

Geroski, Paul A., John Van Reenen, and Chris Walters (2002): "Innovations, Patents and Cash Flow", in Innovation and firm performance: Econometric exploration of survey data, pp. 31-55, Houndmills, U.K. and New York.

Gordon, Robert J. and Ian Dew-Becker (2008): "The role of labor market changes in the slowdown of European productivity growth”, CEPR Discussion Paper, February 2008.

Griffith, Rachel, Stephen Redding, and John Van Reenen (2004): "Mapping the Two Faces of R\&D: Productivity Growth in a Panel of OECD Industries", Review of Economics and Statistics, Vol. 86, No. 4, pp. 883-895.

Griliches, Zvi (1979): "Issues in assessing the contribution of research and development to productivity growth", The Bell Journal of Economics, Vol. 10, No. 1, pp. 92-116. 
Griliches, Zvi (1992): “The Search for R\&D Spillovers”, Scandinavian Journal of Economics, Vol. 94, No. 0, pp. S29-47.

Hall, Bronwyn, Francesca Lotti and Jacques Mairesse (2008): "Employment, innovation and productivity: evidence from Italian microdata", Industrial and Corporate Change, August, Vol. 17, No. 4, pp. 813-39.

Hall, Bronwyn, Jacques Mairesse, Louis Branstetter and Bruno Crépon (1998): "Does cash flow cause Investment and R\&D: An Exploration Using Panel Data for French, Japanese and United States Scientific Firms”, Discussion Paper Nuffield College Oxford n ${ }^{\circ} 42$.

Jones, Benjamin (2010), “Age and Great Invention”, Review of Economics and Statistics, Vol. 92, No. 1, pp.1-14.

Lokshin, Michael and Zurab Sajaia (2004): "Maximum-likelihood estimation of endogenous switching regression models", Stata-journal, Vol. 4, No. 3, pp. 282-289.

Maddala, G. S. (1983): Limited-Dependent and Qualitative Variables in Econometric, Econometric Society Monographs No. 3, Cambridge University Press, New York.

Parisi, Maria Laura, Fabio Schiantarelli and Alessandro Sembenelli (2006): "Productivity, Innovation and R\&D: Micro Evidence for Italy”, European Economic Review, Vol. 50, No. 8, pp. 2037-61.

Van Pottelsberghe de la Potterie, Bruno (2008): "Europe's R\&D: Missing the Wrong Targets?" Intereconomics/Review of European Economic Policy, Vol. 43, No. 4, pp. 220-225.

Verhaeghen, Paul and Timothy A. Salthouse (1997): "Meta-Analyses of Age-Cognition Relations in Adulthood: Estimates of Linear and Nonlinear Age Effects and Structural Models", Psychological Bulletin, Vol. 122, No. 3, pp. 231-249. 


\section{Appendix}

We control for sample selection that could actually come up when Capitalia-Unicredit IX survey data are matched with AIDA balance sheet of firms present in 2007. Not all Capitalia firms exist in AIDA register. Nonetheless, we manage to retain almost $86 \%$ of the Capitalia sample. Therefore, we check in what type of characteristics do firms in-sample and out-of-sample differ.

Figure A 1. In and Out Sample distribution of Capitalia firms by size

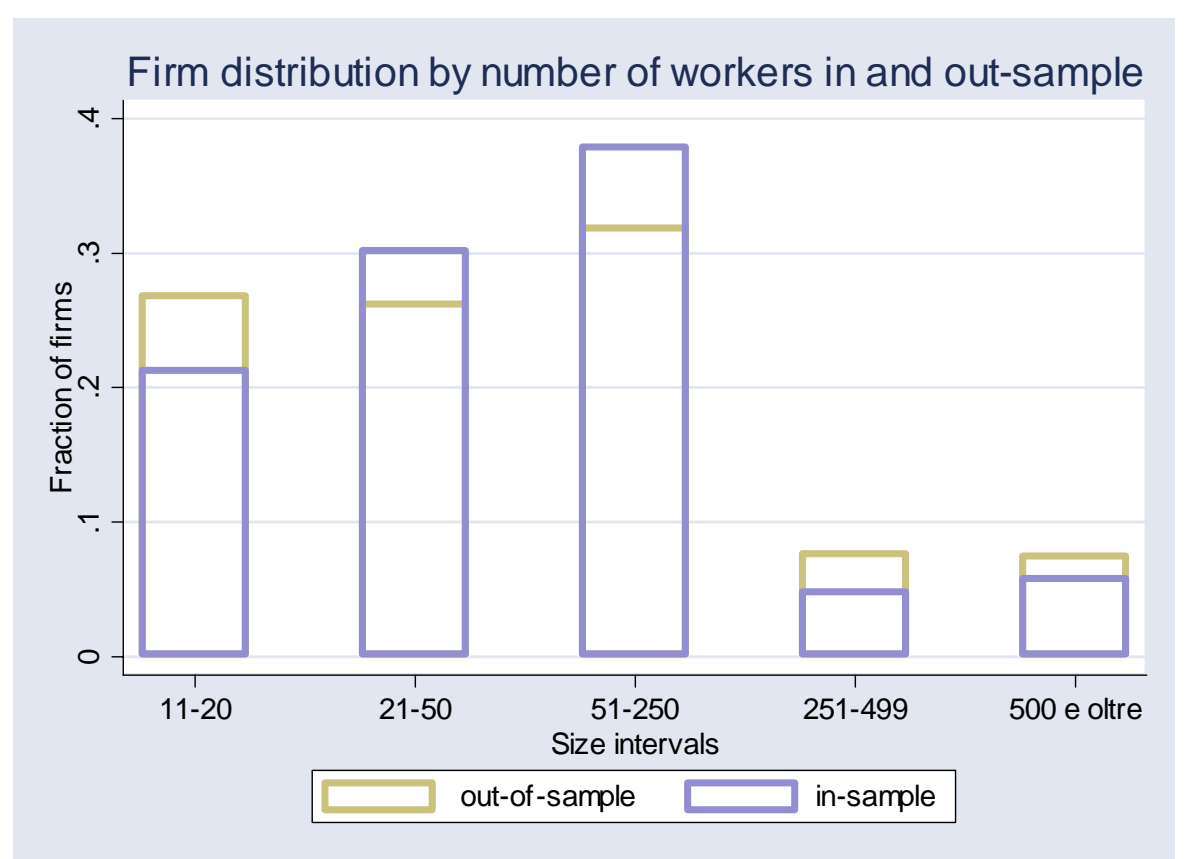

Figure A1 shows the distribution by class of workers of the firms falling in and out of our final panel. The panel tends to maintain medium size firms mainly (87\%), while keeping around $79 \%$ of the medium-large and large firms. As far as the very small firms, our panel keeps $82 \%$ of them. Formally, the test for independence hypothesis rejects the null (Pearson chi-square(4) $=25.7455$, pvalue $=0.000)$ meaning that being in or out of sample depends in a certain way on firm size.

We lose $15.6 \%$ of firms located in North-West part of Italy (Lombardia, Piemonte, Liguria, Valle d'Aosta), 13.9\% of the firms located in the North-East (Trentino A.A., Veneto, Friuli V.G., Emilia Romagna), $13.5 \%$ of the firms located in the Centre (Toscana, Umbria, Marche, Lazio) and 15.8\% of the firms located in the South. The Pearson chi-square $(4)=3.4150$ with $p$-value $=0.491$ says that there is statistical independence between the regional distribution and being in or out of sample. 
Traditional sectors with lower Ateco 1991 code, i.e. Food and Beverages, Textiles, Clothes, Tobacco, tend to be underrepresented with respect to the original Capitalia sample, as we can see from Figure A2. In any case if we consider High-Tech versus the others, there is an independent distribution of frequencies in and out of sample (Pearson chi-square(1) test $=0.3952$ with pvalue $=0.530)$.

We then run a two-sample $t$ test with equal variances to test for equality of average firm age between the two groups (in-sample, out-sample). The results highlight that firms outside the sample are on average 3 years older, and the difference in means is statistically significant.

Figure A 2. Distribution of firms by Ateco 1991 classification, in and out-sample

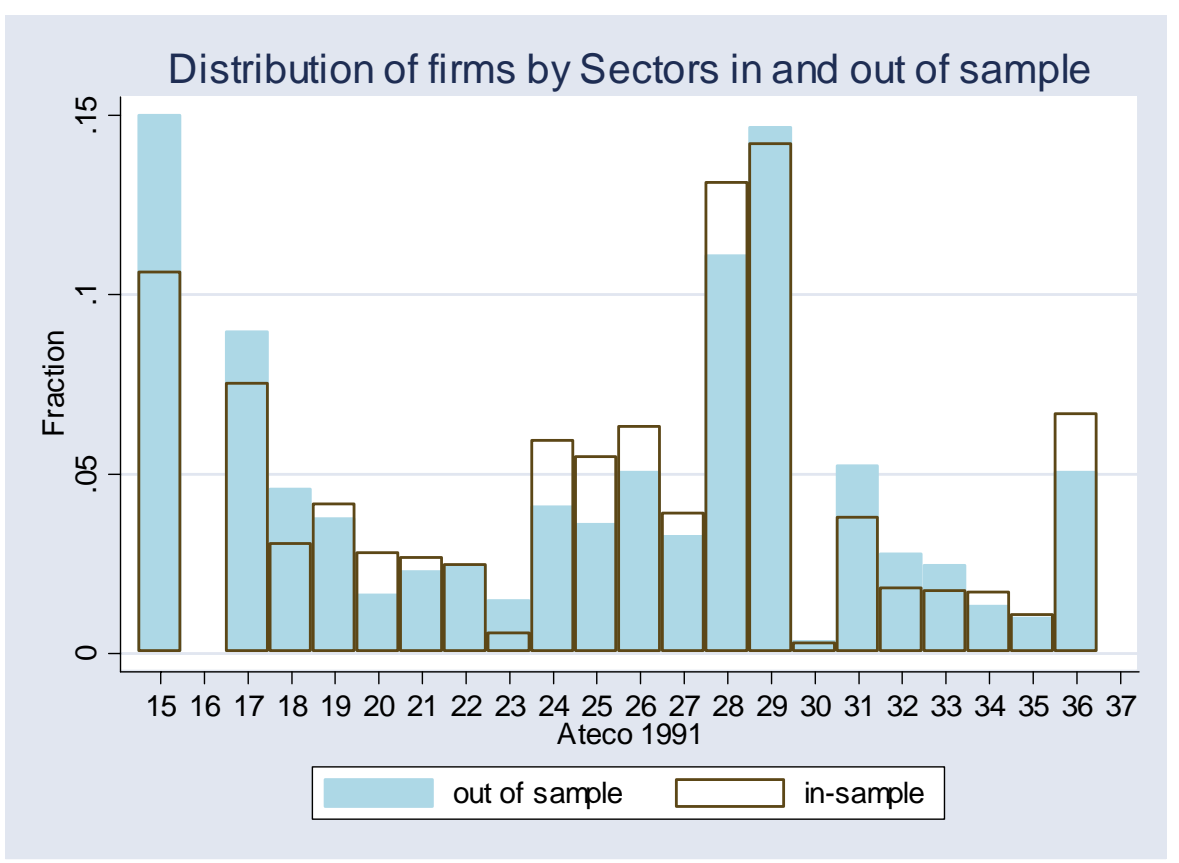

\begin{tabular}{|l|l|l|l|l|l|l|}
\hline Group & Obs & Mean & Std. Err. & Std. Dev. & \multicolumn{2}{|l|}{ [95\% Conf. Interval] } \\
\hline Out sample & 570 & 31.87 & .938 & 22.41 & 30.03 & 33.72 \\
\hline In sample & 3469 & 28.87 & .325 & 19.16 & 28.24 & 29.51 \\
\hline Combined & 4039 & 29.29 & .309 & 19.67 & 28.69 & 29.90 \\
\hline diff & & 3.00 & .887 & & 1.259 & 4.742 \\
\hline
\end{tabular}

Degrees of freedom: 4037 
Ho: $\operatorname{mean}($ out $)-$ mean $($ in $)=\operatorname{diff}=0$

\begin{tabular}{|c|c|c|}
\hline Ha: diff $<0$ & Ha: diff $\neq 0$ & Ha: diff $>0$ \\
\hline $\mathrm{t}=3.3795$ & $\mathrm{t}=3.3795$ & $\mathrm{t}=3.3795$ \\
\hline $\mathrm{P}<\mathrm{t}=0.9996$ & $\mathrm{P}>|\mathrm{t}|=0.0007$ & $\mathrm{P}>\mathrm{t}=0.0004$ \\
\hline
\end{tabular}

Finally, we run an association tests to check for independence between being an innovative firm and being in or out of sample, to evaluate whether less innovative firms are those kicked out of the final panel. The Pearson chi-square tests are listed for different types of innovation activity:

\begin{tabular}{|l|l|}
\hline R\&D expenditures in 2001-2003 (yes/no) & Pearson chi-square $(1)=3.52 \mathrm{p}$-value $=0.061$ \\
\hline Introducing product innovations (yes/no) & Pearson chi-square $(1)=7.194 \mathrm{p}$-value $=0.007$ \\
\hline Introducing process innovations (yes/no) & Pearson chi-square $(1)=2.189 \mathrm{p}$-value $=0.139$ \\
\hline Introducing both process and product & Pearson chi-square $(1)=2.249 \mathrm{p}$-value $=0.134$ \\
innovations (yes/no) & \\
\hline
\end{tabular}

We reject the hypothesis of independence for R\&D expenditure and product innovation only. That means that firms investing into R\&D and introducing product innovations have a (slightly) higher probability to survive. We cannot reject the null for process innovations or both kinds of innovations, instead. Introducing process innovations or not provide a firm equal probability to remain in our sample. 


\section{CESifo Working Paper Series}

for full list see www.cesifo-group.org/wp

(address: Poschingerstr. 5, 81679 Munich, Germany, office@cesifo.de)

3061 Ronald MacDonald and Flávio Vieira, A Panel Data Investigation of Real Exchange Rate Misalignment and Growth, May 2010

3062 Thomas Eichner and Rüdiger Pethig, Efficient Management of Insecure Fossil Fuel Imports through Taxing(!) Domestic Green Energy?, May 2010

3063 Vít Bubák, Evžen Kočenda and Filip Žikeš, Volatility Transmission in Emerging European Foreign Exchange Markets, May 2010

3064 Leonid V. Azarnert, Après nous le Déluge: Fertility and the Intensity of Struggle against Immigration, May 2010

3065 William E. Becker, William H. Greene and John J. Siegfried, Do Undergraduate Majors or Ph.D. Students Affect Faculty Size?, May 2010

3066 Johannes Becker, Strategic Trade Policy through the Tax System, May 2010

3067 Omer Biran and Françoise Forges, Core-stable Rings in Auctions with Independent Private Values, May 2010

3068 Torben M. Andersen, Why do Scandinavians Work?, May 2010

3069 Andrey Launov and Klaus Wälde, Estimating Incentive and Welfare Effects of NonStationary Unemployment Benefits, May 2010

3070 Simon Gächter, Benedikt Herrmann and Christian Thöni, Culture and Cooperation, June 2010

3071 Mehmet Bac and Eren Inci, The Old-Boy Network and the Quality of Entrepreneurs, June 2010

3072 Krisztina Molnár and Sergio Santoro, Optimal Monetary Policy when Agents are Learning, June 2010

3073 Marcel Boyer and Donatella Porrini, Optimal Liability Sharing and Court Errors: An Exploratory Analysis, June 2010

3074 Guglielmo Maria Caporale, Roman Matousek and Chris Stewart, EU Banks Rating Assignments: Is there Heterogeneity between New and Old Member Countries? June 2010

3075 Assaf Razin and Efraim Sadka, Fiscal and Migration Competition, June 2010

3076 Shafik Hebous, Martin Ruf and Alfons Weichenrieder, The Effects of Taxation on the Location Decision of Multinational Firms: M\&A vs. Greenfield Investments, June 2010 
3077 Alessandro Cigno, How to Deal with Covert Child Labour, and Give Children an Effective Education, in a Poor Developing Country: An Optimal Taxation Problem with Moral Hazard, June 2010

3078 Bruno S. Frey and Lasse Steiner, World Heritage List: Does it Make Sense?, June 2010

3079 Henning Bohn, The Economic Consequences of Rising U.S. Government Debt: Privileges at Risk, June 2010

3080 Rebeca Jiménez-Rodriguez, Amalia Morales-Zumaquero and Balázs Égert, The VARying Effect of Foreign Shocks in Central and Eastern Europe, June 2010

3081 Stephane Dees, M. Hashem Pesaran, L. Vanessa Smith and Ron P. Smith, Supply, Demand and Monetary Policy Shocks in a Multi-Country New Keynesian Model, June 2010

3082 Sara Amoroso, Peter Kort, Bertrand Melenberg, Joseph Plasmans and Mark Vancauteren, Firm Level Productivity under Imperfect Competition in Output and Labor Markets, June 2010

3083 Thomas Eichner and Rüdiger Pethig, International Carbon Emissions Trading and Strategic Incentives to Subsidize Green Energy, June 2010

3084 Henri Fraisse, Labour Disputes and the Game of Legal Representation, June 2010

3085 Andrzej Baniak and Peter Grajzl, Interjurisdictional Linkages and the Scope for Interventionist Legal Harmonization, June 2010

3086 Oliver Falck and Ludger Woessmann, School Competition and Students' Entrepreneurial Intentions: International Evidence Using Historical Catholic Roots of Private Schooling, June 2010

3087 Bernd Hayo and Stefan Voigt, Determinants of Constitutional Change: Why do Countries Change their Form of Government?, June 2010

3088 Momi Dahan and Michel Strawczynski, Fiscal Rules and Composition Bias in OECD Countries, June 2010

3089 Marcel Fratzscher and Julien Reynaud, IMF Surveillance and Financial Markets - A Political Economy Analysis, June 2010

3090 Michel Beine, Elisabetta Lodigiani and Robert Vermeulen, Remittances and Financial Openness, June 2010

3091 Sebastian Kube and Christian Traxler, The Interaction of Legal and Social Norm Enforcement, June 2010

3092 Volker Grossmann, Thomas M. Steger and Timo Trimborn, Quantifying Optimal Growth Policy, June 2010 
3093 Huw David Dixon, A Unified Framework for Using Micro-Data to Compare Dynamic Wage and Price Setting Models, June 2010

3094 Helmuth Cremer, Firouz Gahvari and Pierre Pestieau, Accidental Bequests: A Curse for the Rich and a Boon for the Poor, June 2010

3095 Frank Lichtenberg, The Contribution of Pharmaceutical Innovation to Longevity Growth in Germany and France, June 2010

3096 Simon P. Anderson, Øystein Foros and Hans Jarle Kind, Hotelling Competition with Multi-Purchasing: Time Magazine, Newsweek, or both?, June 2010

3097 Assar Lindbeck and Mats Persson, A Continuous Theory of Income Insurance, June 2010

3098 Thomas Moutos and Christos Tsitsikas, Whither Public Interest: The Case of Greece's Public Finance, June 2010

3099 Thomas Eichner and Thorsten Upmann, Labor Markets and Capital Tax Competition, June 2010

3100 Massimo Bordignon and Santino Piazza, Who do you Blame in Local Finance? An Analysis of Municipal Financing in Italy, June 2010

3101 Kyriakos C. Neanidis, Financial Dollarization and European Union Membership, June 2010

3102 Maela Giofré, Investor Protection and Foreign Stakeholders, June 2010

3103 Andrea F. Presbitero and Alberto Zazzaro, Competition and Relationship Lending: Friends or Foes?, June 2010

3104 Dan Anderberg and $\mathrm{Yu}$ Zhu, The Effect of Education on Martial Status and Partner Characteristics: Evidence from the UK, June 2010

3105 Hendrik Jürges, Eberhard Kruk and Steffen Reinhold, The Effect of Compulsory Schooling on Health - Evidence from Biomarkers, June 2010

3106 Alessandro Gambini and Alberto Zazzaro, Long-Lasting Bank Relationships and Growth of Firms, June 2010

3107 Jenny E. Ligthart and Gerard C. van der Meijden, Coordinated Tax-Tariff Reforms, Informality, and Welfare Distribution, June 2010

3108 Vilen Lipatov and Alfons Weichenrieder, Optimal Income Taxation with Tax Competition, June 2010

3109 Malte Mosel, Competition, Imitation, and R\&D Productivity in a Growth Model with Sector-Specific Patent Protection, June 2010 
3110 Balázs Égert, Catching-up and Inflation in Europe: Balassa-Samuelson, Engel's Law and other Culprits, June 2010

3111 Johannes Metzler and Ludger Woessmann, The Impact of Teacher Subject Knowledge on Student Achievement: Evidence from Within-Teacher Within-Student Variation, June 2010

3112 Leif Danziger, Uniform and Nonuniform Staggering of Wage Contracts, July 2010

3113 Wolfgang Buchholz and Wolfgang Peters, Equity as a Prerequisite for Stable Cooperation in a Public-Good Economy - The Core Revisited, July 2010

3114 Panu Poutvaara and Olli Ropponen, School Shootings and Student Performance, July 2010

3115 John Beirne, Guglielmo Maria Caporale and Nicola Spagnolo, Liquidity Risk, Credit Risk and the Overnight Interest Rate Spread: A Stochastic Volatility Modelling Approach, July 2010

3116 M. Hashem Pesaran, Predictability of Asset Returns and the Efficient Market Hypothesis, July 2010

3117 Dorothee Crayen, Christa Hainz and Christiane Ströh de Martínez, Remittances, Banking Status and the Usage of Insurance Schemes, July 2010

3118 Eric O’N. Fisher, Heckscher-Ohlin Theory when Countries have Different Technologies, July 2010

3119 Huw Dixon and Hervé Le Bihan, Generalized Taylor and Generalized Calvo Price and Wage-Setting: Micro Evidence with Macro Implications, July 2010

3120 Laszlo Goerke and Markus Pannenberg, 'Take it or Go to Court' - The Impact of Sec. 1a of the German Protection against Dismissal Act on Severance Payments -, July 2010

3121 Robert S. Chirinko and Daniel J. Wilson, Can Lower Tax Rates be Bought? Business Rent-Seeking and Tax Competition among U.S. States, July 2010

3122 Douglas Gollin and Christian Zimmermann, Global Climate Change and the Resurgence of Tropical Disease: An Economic Approach, July 2010

3123 Francesco Daveri and Maria Laura Parisi, Experience, Innovation and Productivity Empirical Evidence from Italy's Slowdown, July 2010 